\title{
Rising antipsychotic prescriptions for children and youth: cross-sectoral solutions for a multimodal problem
}

\author{
Nina Di Pietro PhD, Judy Illes PhD; for the Canadian Working Group on Antipsychotic Medications and Children*
}

I $\mathrm{n}$ the past 10 years, off-label prescribing of antipsychotic medications to Canadian children and youth has risen dramatically despite a lack of strong evidence for efficacy and serious adverse effects. ${ }^{1-5}$ According to Canadian pharmacoepidemiologic data, antipsychotic medications have been prescribed for the treatment of attentiondeficit/hyperactivity disorder (17\%), mood and conduct disorders $(14 \%-16 \%)$ and psychosis $(13 \%)$ in young people. ${ }^{4}$ Currently, aripiprazole, a second-generation antipsychotic drug, is approved in Canada for the treatment of bipolar I disorder (manic or mixed episodes) in youth 13-17 years old and for schizophrenia in those 15-17 years old. In the United States, the Food and Drug Administration has approved a number of secondgeneration antipsychotic medications for the treatment of bipolar disorder, schizophrenia, and irritability (in the context of autism) in youth. ${ }^{6}$ Prescriptions of antipsychotic medications for nonpsychotic conditions, such as attentiondeficit/hyperactivity disorder, disruptive behaviour and nonspecific mood problems, however, are considered off-label and are not approved by Health Canada for these indications. The evidence for the efficacy of these off-label indications is limited for children and youth. ${ }^{5}$ Moreover, the upswing in off-label prescriptions is paralleled by safety concerns related to adverse events, such as weight gain, diabetes, hyperprolactinemia and abnormal movements (e.g., tardive dyskinesia). ${ }^{6,7}$

In September 2013, the American Psychiatric Association sought to address health and safety concerns regarding the off-label use of antipsychotic medications in the US by publishing a list of best practices for prescribing antipsychotic drugs as part of an initiative called Choosing Wisely. ${ }^{8}$ The American Psychiatric Association's list of best practices applies to both adults and children. It emphasizes the importance of the initial evaluation and ongoing monitoring, limiting concurrent prescriptions of antipsychotic medications, careful selection of first-line interventions and adherence to evidence-based practices. These recommendations complement the guidelines of the Canadian Alliance for Monitoring Effectiveness and Safety of Antipsychotics in Children ${ }^{9}$ and the position statement released by the Canadian Paediatric Society. ${ }^{10}$ Nevertheless, we believe that efforts to heed these recommendations, including those put forward by the American Psychiatric Association, face daunting challenges.

The increase in the number of prescriptions for antipsychotic medications to children and youth reflects complex societal, economic, political and cultural issues. Not the least of these is widespread enthusiasm for the future promises of the neurosciences and for molecular medicine, imagined in terms of targeted drug interventions to ameliorate behavioural and emotional problems.

How do we remedy the problem of off-label prescribing of antipsychotic medications? As a start, we need to have a broader conversation about the affordability and accessibility of effective nonpharmacologic health services such as parenttraining programs, cognitive behavioural therapy and social-skills training that support youth and their families with lived experiences of mental illness. Health care professionals need to be committed to working with all stakeholders in the community, including teachers, youth, parents and other health providers. By engaging communities in actions that are known to foster well-being, stakeholders will be empowered and existing strengths promoted. Such coordinated cross-sectoral approaches have been initiated in Canada, including community-based partnerships to identify alternate effective treatments, to delineate procedures

\section{KEY POINTS}

- Off-label prescribing of antipsychotic medications to treat mood and behavioural disorders in Canadian children and youth has increased dramatically despite concerns regarding a lack of strong evidence for efficacy and serious adverse events.

- The rise in off-label prescriptions in this population reflects complex societal, economic, political and cultural issues.

- Several health and education programs have been initiated in Canada to try to address safety concerns and promote community engagement for better mental health care.

- To reduce off-label prescribing of antipsychotic medications, Canadian physicians need to advocate for affordable access to effective solutions from a range of health services that support the mental health of youth and their families. 
and evidence for guidance on the use of secondgeneration antipsychotic drugs and to address safety concerns.

British Columbia, for example, has funded the dedicated Provincial Mental Health Metabolic Program at BC Children's Hospital to help monitor and mitigate the adverse effects associated with antipsychotic medications in children and youth. This program has developed many resources, including Healthy Living, Healthy Minds: a Toolkit for Health Professionals and the Healthy Living Toolkit for Families (www.keltymentalhealth.ca). To help doctors identify and manage adverse effects, the Canadian Alliance for Monitoring Effectiveness and Safety of Antipsychotics in Children developed guidelines (http://camesaguideline.org/) with input from a variety of stakeholders, including health professionals and patients. Educational curricula are also being created for medical residents across Canada to teach them about the appropriate assessment and management of aggression in children and youth with disruptive behaviour disorders, with the goal of decreasing antipsychotic medication use in this population. In addition, Therapeutic Products for Infants, Children, and Youth is an assessment (www.scienceadvice.ca /en/assessments/in-progress/therapeutic-products .aspx) by the Council of Canadian Academies at the request of Health Canada that is reviewing therapeutic products for children in Canada for the ethical development of safe and effective pharmaceuticals and the labelling of therapies. In Nova Scotia, a project called More than Meds (www .morethanmeds.com) is capitalizing on the knowledge and skills of community pharmacists in partnership with people with lived experiences of mental illness in their communities to provide support for navigating the health system, better care to individuals and families, and educational outreach to communities.

We are mindful that the use of antipsychotic drugs in children and youth reflects knowledge gaps that may be reduced through innovations in clinical and neuroscience research in the long term. Although it is important to be optimistic about the future of pharmacologic interventions, clinicians need to bridge the gap between the limits of scientific evidence and the immediate needs of patients, particularly in the area of antipsychotic prescribing to children and youth. Canadian physicians and other health professionals must continue to advocate strongly for access to cross-modal interventions, including nonpharmacologic ones, and not look too narrowly to molecules for solutions.

\section{References}

1. Alessi-Severini S, Biscontri RG, Collins DM, et al. Ten years of antipsychotic prescribing to children: a Canadian populationbased study. Can J Psychiatry 2012;57:52-8.

2. Olfson M, Blanco C, Liu L, et al. National trends in the outpatient treatment of children and adolescents with antipsychotic drugs. Arch Gen Psychiatry 2006;63:679-85.

3. Pringsheim T, Lam D, Patten SB. The pharmacoepidemiology of antipsychotic medications for Canadian children and adolescents: 2005-2009. J Child Adolesc Psychopharmacol 2011;21: 537-43.

4. Zito JM, Safer DJ, de Jong-van den Berg LTW, et al. A threecountry comparison of psychotropic medication prevalence in youth. Child Adolesc Psychiatry Ment Health 2008;2:26.

5. Pringsheim T, Gorman D. Second-generation antipsychotics for the treatment of disruptive behaviour disorders in children: a systematic review. Can J Psychiatry 2012;57:722-7.

6. Panagiotopoulos C, Ronsley R, Elbe D, et al. First do no harm: promoting an evidence-based approach to atypical antipsychotic use in children and adolescents. J Can Acad Child Adolesc Psychiatry 2010;19:124-37.

7. Pringsheim T, Lam D, Ching $\mathrm{H}$, et al. Metabolic and neurological complications of second-generation antipsychotic use in children: a systematic review and meta-analysis of randomized controlled trials. Drug Saf 2011;34:651-68.

8. Five things physicians and patients should question. Arlington (VA): American Psychiatric Association; 2013. Available: www.psychiatry.org/choosingwisely (accessed 2013 Oct. 12).

9. Pringsheim T, Panagiotopoulos C, Davidson J, et al. Evidencebased recommendations for monitoring safety of second generation antipsychotics in children and youth. J Can Acad Child Adolesc Psychiatry 2011;20:218-33.

10. Rieder RJ; Canadian Paediatric Society, Drug Therapy and Hazardous Substances Committee. Drug research and treatment for children in Canada: a challenge. Paediatr Child Health 2011; 16:560-1.

Affiliation: National Core for Neuroethics, University of British Columbia, Vancouver, BC.

Contributors: All of the authors contributed substantially to the writing and revising of the manuscript and approved the final version submitted for publication. All of the authors are guarantors of the work.

Acknowledgements: Funding and support for the Canadian Working Group on Antipsychotic Medications and Children was provided by the Peter Wall Institute for Advanced Studies at the University of British Columbia, NeuroDevNet, Inc., the National Core for Neuroethics at the University of British Columbia and the Vancouver Coastal Health Research Institute. An earlier opinion piece related to this commentary was published for the public in the Vancouver Sun on Nov. 27, 2013.

Members of the Canadian Working Group on Antipsychotic Medications and Children who contributed to this article: Lori d'Agincourt-Canning PhD, Department of Pediatrics, University of British Columbia, Vancouver, BC; Bruce Carleton PharmD, Department of Paediatrics, University of British Columbia; Daniel Gorman MD, Department of Psychiatry, University of Toronto, Toronto, Ont.; Charlotte Johnston PhD, Department of Psychology, University of British Columbia; Andrea Murphy PharmD, College of Pharmacy, Dalhousie University, Halifax, NS; Constadina Panagiotopoulos MD, Department of Paediatrics, University of British Columbia; Tamara Pringsheim MD MSc, Department of Clinical Neurosciences, Psychiatry, Pediatrics and Community Health Sciences, University of Calgary, Calgary, Alta.; Benjamin Wilfond MD, Division of Bioethics, Department of Pediatrics, and Department of Bioethics and Humanities, University of Washington, Washington, DC. For the complete list of members of the working group, see Appendix 1 (available at www.cmaj.ca/lookup/suppl/doi:10.1503 /cmaj.131604/-/DC1). 